\title{
Status of Studies Investigating Asthma- Chronic Obstructive Pulmonary Disease Overlap in Korea: A Review
}

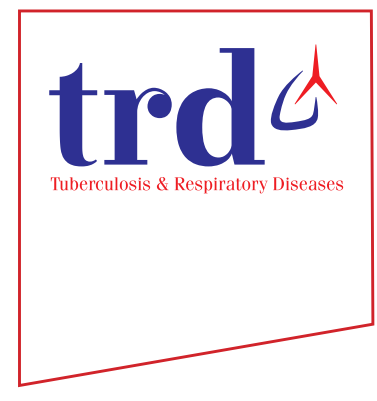

\author{
Yong Suk Jo, M.D. ${ }^{\text {D }}$ \\ Division of Pulmonary and Critical Care Medicine, Department of Internal Medicine, Seoul St. Mary's Hospital, College of \\ Medicine, The Catholic University of Korea, Seoul, Republic of Korea
}

There is a considerable number of individuals who exhibit features of both asthma and chronic obstructive pulmonary disease (COPD), defined as asthma-COPD overlap (ACO). Many studies have reported that these patients have a greater burden of symptoms, including cough and dyspnea, and experience more exacerbations and hospitalizations than those with non-ACO COPD or asthma. Although diagnostic criteria for ACO have not yet been clearly established, their clinical significance remains to be determined. As interest in ACO grows, related studies have been conducted in South Korea as well. The present review summarizes ACO-related studies in South Korea to better understand Korean ACO patients and guide further research. Several cohort studies of asthma and COPD and population-based studies for ACO were reviewed and the key results from demographics, clinical features, lung function, biomarkers, treatment, and prognosis were summarized.

Keywords: Asthma; Pulmonary Disease, Chronic Obstructive; Overlap; South Korea

\section{Introduction}

Although asthma and chronic obstructive pulmonary disease (COPD) were traditionally believed to be distinctive chronic airway diseases, with different pathophysiologies, a significant number of patients exhibit features of both. Since Gibson and Simpson ${ }^{1}$ first described asthma-COPD overlap

Address for correspondence: Yong Suk Jo, M.D.

Division of Pulmonary and Critical Care Medicine, Department of Internal Medicine, Seoul St. Mary's Hospital, College of Medicine, The Catholic University of Korea, 222 Banpo-daero, Seocho-gu, Seoul 06591, Republic of Korea

Phone: 82-2-2258-6060, Fax: 82-2-599-3589

E-mail: lucidyonge@gmail.com

Received: Sep. 13, 2021

Revised: Oct. 10, 2021

Accepted: Dec. 2, 2021

Published online: Dec. 6, 2021

(c) It is identical to the Creative Commons Attribution Non-Commercial License (http://creativecommons.org/licenses/by-nc/4.0/).
(ACO), a considerable number of studies have investigated this disease entity. However, it is difficult to obtain consistent information for ACO patients because individuals simultaneously exhibiting features of both asthma and COPD were excluded from clinical studies investigating either of the two diseases; furthermore, because there are no unified diagnostic criteria for ACO, it is difficult to understand. Although there are many COPD or asthma cohorts worldwide, the prevalence and clinical features vary depending on the criteria used to define ACO. Many cohorts have been defined as ACO by applying "homemade" diagnostic criteria, as the diagnostic approach for ACO proposed by the Global Initiative for Asthma $(\mathrm{GINA})^{2}$ is difficult to apply in clinical practice. It remains controversial whether ACO is distinctive from asthma and COPD, or one of the phenotypes of either disease, however, interest in ACO is high, and related studies in clinical practice are ongoing.

The present review summarizes the current state of ACO studies in South Korea, and contributes towards a more comprehensive understanding of Korean patients with ACO. The epidemiology and clinical manifestations of ACO are reviewed, and outcomes, including exacerbation(s), lung function decline, and the effect of treatment on prognosis, are discussed. 


\section{Epidemiology of ACO}

There are asthma and COPD cohorts in Korea; however, the prevalence of ACO varies according to the criteria adapted to each cohort (Table 1). In two asthma cohorts exhibiting bronchodilator response (BDR) or airway hyper-responsiveness (AHR) positivity, ACO was defined as concomitant fixed airflow obstruction (post-bronchodilator forced expiratory volume in 1 second $\left[\mathrm{FEV}_{1}\right] /$ forced vital capacity $[\mathrm{FVC}]$ ratio $<0.7$ ) for 3 months from baseline. These studies identified 97 of 256 $(38 \%)^{3}$ and 228 of $959(23.8 \%)^{4}$ patients with ACO. In the Korean Severe Asthma Registry (KoSAR), ACO was diagnosed through a questionnaire administered to attending specialists comprising allergy or pulmonary physicians, with 114 of 482 $(23.7 \%)$ patients classified as ACO ${ }^{5}$. Individuals with ACO were predominantly male, and prevalence tended to increase with advancing age. This study also investigated the main factors that affected the diagnosis of ACO, with three clinical features being particularly relevant: history of smoking, fixed airflow limitation, and BDR positivity at any time. The most influential factors contributing to ACO diagnosis were smoking history (76\%), fixed airflow limitation (55\%), and BDR positiv- ity $(41 \%)$.

A single-center study that included 2,933 COPD patients with suspected ACO according to the GINA document, identified 767 patients $(26.2 \%)$ with ACO $^{6}$. A COPD cohort study from three hospitals defined ACO according to suggestions from four different sources- modified Spanish ${ }^{7}$, American Thoracic Society (ATS) roundtable ${ }^{8}$, PLATINO (a Spanish acronym for the Latin American Project for Research in Pulmonary Obstruction $)^{9}$, and 2017 updated GINA/Global Initiative for COPD (GOLD) recommendations. It was reported that $31.3 \%, 11.9 \%, 48.3 \%$, and $46.1 \%$ of COPD patients, respectively, were diagnosed with $\mathrm{ACO}^{10}$. Cluster analysis using six variables (age, body mass index [BMI], $\mathrm{FEV}_{1} \%$ predicted, self-reported wheezing, smoking status, and pack-years [PYs] smoking) in the Korean National Health and Nutrition Examination Survey (KNHANES) database included patients with airflow limitation and $\mathrm{FEV}_{1} \geq 60 \%{ }^{11}$. Of the 2140 subjects, the asthma-predominant overlap was 893 (42\%), and the COPDpredominant overlap was 586 (27\%). The Korean COPD subgroup study (KOCOSS) is a prospective cohort study of patients with COPD from 48 referral hospitals in the Republic of Korea. Out of the 1,504 COPD patients, ACO was diagnosed

Table 1. Prevalence of ACO

\begin{tabular}{|c|c|c|c|}
\hline Citation & No. of patients & ACO definition & Prevalence of ACO, n (\%) \\
\hline Lee et al. $(2014)^{3}$ & 256 Asthma patients & $\begin{array}{l}\text { BDR }>200 \mathrm{~mL} \text { and } 12 \% \text { or positive provocation test } * \text { and } \\
\text { post-BD } \mathrm{FEV}_{1} / \mathrm{FVC}<0.70\end{array}$ & $97(38)$ \\
\hline Park et al. $(2019)^{4}$ & 959 Asthma patients & $\begin{array}{l}\text { BDR }>200 \mathrm{~mL} \text { and } 12 \% \text { or positive provocation test }{ }^{*} \text { and } \\
\text { post-BD } \mathrm{FEV}_{1} / \mathrm{FVC}<0.70\end{array}$ & $228(23.8)$ \\
\hline Lee et al. $(2021)^{5}$ & $\begin{array}{l}482 \text { Severe asthma } \\
\text { patients }\end{array}$ & Specialist-diagnosed asthma-COPD overlap & $114(23.7)$ \\
\hline Kim et al. $(2015)^{6}$ & 2,933 COPD patients & $\begin{array}{l}\text { Post-BD } \mathrm{FEV}_{1} / \mathrm{FVC}<0.7 \text { and asthma was diagnosed } \\
\text { according to the GINA definition }\end{array}$ & $767(26.2)$ \\
\hline Park et al. $(2017)^{12}$ & 1,504 COPD patients & Post-BD FEV $/$ /FVC $<0.7$ and BDR $>200 \mathrm{~mL}$ and $200 \mathrm{~mL}$ & $223(14.8)$ \\
\hline Jo et al. $(2017)^{10}$ & 301 COPD patients & $\begin{array}{l}\text { Modified Spanish criteria ( } 7 \text { ) } \\
\text { ATS Roundtable criteria (8) } \\
\text { PLATINO criteria (9) } \\
\text { GINA/GOLD criteria ( } 2017 \text { updated) }\end{array}$ & $\begin{array}{l}91 / 291(31.3) \\
5 / 42(11.9) \\
140 / 290(48.3) \\
42 / 91(46.1)\end{array}$ \\
\hline Jo et al. $(2020)^{13}$ & 1,067 COPD patients & $\begin{array}{l}\text { Modified Spanish criteria ( } 7 \text { ) } \\
\text { ATS Roundtable criteria (8) } \\
\text { GINA/GOLD criteria (2019 updated) } \\
\text { Updated Spanish (13) }\end{array}$ & $\begin{array}{l}171 / 992(16.0) \\
32 / 873(3.0) \\
138 / 1067(12.9) \\
221 / 730(20.7)\end{array}$ \\
\hline Lee et al. $(2017)^{11}$ & $\begin{array}{l}\text { 2,140 of KNHANES } \\
\text { database }\end{array}$ & $\begin{array}{l}\mathrm{FEV}_{1} \geq 60 \% \text { of predicted and } \mathrm{FEV}_{1} / \mathrm{FVC}<0.7 \\
\mathrm{Clustering} \text { analysis using } 6 \text { key input variables: age, BMI, } \\
\mathrm{FEV}_{1} \% \text { predicted, self-reported wheezing, smoking } \\
\text { status, and pack-years of smoking }\end{array}$ & $\begin{array}{l}893 \text { Asthmatic-predominant } \\
\text { overlap }(42 \%) \text {, } \\
586 \text { COPD-predominant } \\
\text { overlap }(27 \%)\end{array}$ \\
\hline
\end{tabular}

*Positive methacholine results were defined as the provocative concentration of methacholine required to decrease $\mathrm{FEV}_{1}(\mathrm{PC} 20)$ by $20 \%$ less than or equal to $16 \mathrm{mg} / \mathrm{mL}^{14}$ and Positive mannitol results were defined as $\mathrm{PD}_{15}$ less than or equal to $635 \mathrm{mg}^{15}$.

ACO: asthma-chronic obstructive pulmonary disease overlap; BDR: bronchodilator response; BD: bronchodilator; $\mathrm{FEV}_{1}$ : forced expiratory volume in 1 second; FVC: forced vital capacity; COPD: chronic obstructive pulmonary disease; GINA: Global Initiative for Asthma; ATS: American Thoracic Society; PLATINO: Spanish acronym for the Latin American Project for Research in Pulmonary Obstruction; GOLD: Global Initiative for COPD; KNHANES: Korean National Health, and Nutrition Examination Survey; BMI: body mass index. 
in 223 (14.8\%) according to BDR positivity alone ${ }^{12}$; however, when five different diagnostic criteria were applied, ACO was diagnosed in 138 out of the 1,067 patients (12.9\%) according to GINA/GOLD, 32 out of $873(3.0 \%)$ according to the ATS roundtable, 171 out of $992(16.0 \%)$ according to the modified Spanish, and 221 out of $730(20.7 \%)$ according to the updated Spanish criteria $^{13,16}$.

\section{Clinical Characteristics of ACO}

The recently updated GINA guideline states that there is broad agreement for ACO that those patients have a greater burden of symptoms and poor quality of life (QoL), experience frequent exacerbations, have a more rapid decline in lung function, use healthcare resources more, and have higher mortality compared to those with asthma or COPD alone ${ }^{2}$. In recent years, several studies have investigated ACO in South Korea, and the clinical features reported varied according to the definition of ACO and across cohorts.

In two asthma cohorts ${ }^{3,4}$, ACO patients were older, more often male, and more often former smokers than those with asthma alone. The KoSAR cohort also reported that ACO patients were older, predominantly male, and more often smokers than patients with severe asthma. However, there was no significant difference in QoL between patients with severe asthma and those with $\mathrm{ACO}^{5}$.

Across studies involving COPD cohorts, the clinical features of ACO and COPD alone were reported slightly differently. Some studies reported that ACO patients were older and more often male and smokers than those with COPD alone $^{11,12}$. In contrast, others reported that ACO patients were less male predominant with less smoking than patients with COPD alone ${ }^{6,13}$. Several studies have reported that ACO patients have a poorer QoL status than those with COPD or asthma alone, according to indexes of QoL measurement tools for asthma or COPD ${ }^{10,12,17,18}$.

Regarding exacerbation history within one year before enrollment, several COPD cohort studies have reported that ACO patients experienced more moderate or severe exacerbation(s) compared with COPD alone ${ }^{10,13,19}$. Similarly, patients with ACO experienced more exacerbations, required steroid burst therapy, emergency room visits, or hospitalization than those with severe asthma ${ }^{5}$. However, some studies reported no differences in exacerbation between patients with ACO and those with $\mathrm{COPD}^{20,21}$. Moreover, one study reported fewer previous exacerbation events in patients with ACO than in those with COPD alone, although the difference was not statistically significant ${ }^{12}$.

\section{Lung Function}

Two asthma studies reported lower $\mathrm{FEV}_{1}$ and $\mathrm{FEV}_{1} / \mathrm{FVC}$ ratios in patients with ACO than in those with asthma ${ }^{3,4}$. Moreover, ACO patients exhibited a low provocation concentration causing a $20 \%$ fall in $\mathrm{FEV}_{1}\left(\mathrm{PC}_{20}\right)$ or provocation dose causing a $15 \%$ decrease in $\mathrm{FEV}_{1}\left(\mathrm{PD}_{15}\right)$ compared with asthmatic patients. One asthma study measured lung volume and revealed that ACO patients have higher functional residual capacity and residual volume than asthmatic patients ${ }^{3}$. In the Cohort for Reality and Evolution of Adult Asthma in Korea (COREA) cohort study, there was higher BDR positivity in patients with ACO than in those with asthma ${ }^{4}$. Specialist-diagnosed ACO patients in the KoSAR cohort had lower $\mathrm{FEV}_{1}, \mathrm{FVC}$, and $\mathrm{FEV}_{1} / \mathrm{FVC}$ ratios than patients with severe asthma; however, fractional exhaled nitric oxide values were similar in the two groups 5 .

Among studies of COPD cohorts, contradictory results regarding lung function measurements have been reported. Some studies reported that those with ACO exhibited lower $\mathrm{FEV}_{1}, \mathrm{FVC}$, and a lower $\mathrm{FEV}_{1} / \mathrm{FVC}$ ratio $^{6,17}$, while others reported that, those with ACO had higher $\mathrm{FEV}_{1}$, higher FVC, and higher $\mathrm{FEV}_{1} / \mathrm{FVC}$ ratio than those with COPD alone ${ }^{10,13,22}$. However, more BDR positivity has been consistently observed in patients with ACO than in those with COPD across studies $^{6,10,13,22}$.

\section{Comorbid Conditions of ACO}

ACO studies using a nationally representative database including the National Health Insurance (NHI) and the KNHANES defined ACO according to the International Classification of Diseases, 10th revision (ICD-10) codes for COPD and asthma. The studies reported that ACO patients often exhibit ischemic heart disease, diabetes mellitus, hypertension, psychiatric disorders (e.g., depression and anxiety), and osteoporosis more frequently than those with COPD alone ${ }^{19,20}$. Other studies using the KNHANES database defined ACO based on the history of asthma diagnosis or subjective wheezing. The studies also reported that individuals with ACO had a lower BMI that was accompanied by osteoporosis and sarcopenia as comorbid conditions, compared to those with COPD ${ }^{17,23,24}$. Among the KoSAR cohorts, individuals with ACO have less allergic rhinitis or chronic rhinosinusitis and aspirin intolerance, but more hypertension and a history of pulmonary tuberculosis compared with patients with severe asthma ${ }^{5}$. In contrast, ACO patients more often had a history of asthma, atopy, and allergic rhinitis as comorbid conditions than those with COPD alone in the KOCOSS cohort ${ }^{13}$. 


\section{Biomarkers}

\section{Blood eosinophils}

Two studies involving cohorts with asthma defined ACO according to BDR or AHR positivity with fixed airflow limitation reported inconsistent results on blood eosinophil levels between those with asthma and ACO. Lee et al. ${ }^{3}$ reported that ACO patients had lower blood eosinophil counts compared to those with asthma alone; however, Park et al. ${ }^{4}$ reported no significant difference in blood eosinophil levels between the two groups. In the KoSAR cohort, patients with ACO had lower blood eosinophil levels but higher neutrophil counts than those with asthma alone, with no differences in the proportion of sputum eosinophils between the groups ${ }^{5}$.

Individuals with ACO in the two COPD cohorts exhibited higher blood eosinophil counts than those with COPD alone. In addition, total IgE levels were higher in patients with ACO than in those with COPD alone $e^{10,13}$.

\section{Urine L-histidine and serum club cell secretory protein 16}

One small prospective cohort of patients with chronic airway disease, including patients aged $\geq 19$ years in a stable state for $>3$ months, analyzed urinary L-histidine and serum club cell secretory protein 16 (CC-16) using liquid chromatography-mass spectrometry and metabolomic analysis, or enzyme-linked immunosorbent assay (ELISA). This cohort comprised 32 asthma, 38 COPD, and 37 ACO patients diagnosed based on the GesEPOC (the Spanish COPD guidelines) and GEMA (Spanish Guidelines for the Management of Asthma) algorithms ${ }^{25}$. Urinary L-histidine levels were higher in individuals with ACO than in those with asthma or COPD alone even when the ACO group was subdivided into smoking-related obstructive asthma ( $\mathrm{n}=27)$ and COPD with highly positive BDR and/or blood eosinophilia $(n=10)$, urinary L-histidine levels were higher in both groups than those with asthma or $\mathrm{COPD}^{26}$. In addition, serum CC-16 levels were lower in patients with ACO, especially in those with frequent exacerbations ${ }^{27}$. The authors suggested that urinary L-histidine and serum CC-16 are potential biomarkers for ACO, regardless of the diversity of diagnostic criteria used or discrimination of frequent exacerbators.

\section{Neutrophil gelatinase-associated lipocalin}

Of the 137 patients from the COPD in the Dusty Areas (CODA) cohort, 77 had ACO based on positive BDR or previous history of asthma, and plasma neutrophil gelatinaseassociated lipocalin (NGAL) levels were analyzed using ELISA. NGAL levels were higher in females with ACO $(17.0 \pm 6.4 \mathrm{ng} / \mathrm{mL}$ vs. $11.1 \pm 4.5 \mathrm{ng} / \mathrm{mL}, \mathrm{p}=0.01$ ), and it demonstrated favorable pre- dictive ability to discriminate ACO from non-ACO COPD (area under the receiver operating characteristic curve [AUROC], 0.79), which was similar to blood eosinophil level (AUROC, $0.79)^{28}$.

\section{Genome-Wide Association Study in an Asthma Cohort}

Among the COREA cohort, genetic information was available for 1,433 patients comprising of those with ACO $(n=77)$ and those with asthma $(n=1,356)$. There were no significant single nucleotide polymorphisms that could discriminate ACO from asthma ${ }^{4}$.

\section{Imaging}

The Korean Obstructive Lung Disease (KOLD) study provides volumetric computed tomography (CT) scan measurements, and the emphysema index (EI), defined as the percentage of low attenuation area $\leq 950$ Hounsfield units (HU), and airway thickening according to mean wall area (MWA; percentage of two segmental bronchi), were derived using inhouse software from the KOLD study ${ }^{29}$. Those with ACO (47 of 239 COPD patients) had a lower proportion of emphysema compared to those with COPD alone ( $17.1 \%$ vs. $22.1 \%$, respectively; $\mathrm{p}=0.044)^{22}$. The CODA study also provides volumetric CT scan measurements based on the KOLD study, and those with ACO in the CODA cohort $(\mathrm{n}=77)$ exhibited a lower EI ( $7.9 \%$ vs. 9.7\%, $\mathrm{p}=0.06$ ) compared to those with COPD alone; however, there was no difference in MWA $(\%)^{28}$.

Hwang et al. ${ }^{30}$ assessed regional ventilation abnormalities in patients with ACO $(\mathrm{n}=21)$ and COPD $(\mathrm{n}=46)$ using xenonventilation dual-energy CT and quantified EI, airway wall thickness (Pi10), and mean ventilation values. There were three patterns: (1) peripheral wedge/diffuse defects, (2) diffuse heterogeneous defects, and (3) lobar/segmental/subsegmental defects. ACO was more common in pattern 1 , and COPD was more common in patterns 2 and 3 . The degree of peripheral lung ventilation was lower in the ACO group than in the non-ACO group (21.3 HU vs. $22.8 \mathrm{HU}, \mathrm{p}=0.045)$. On the other hand, the EI was lower in the ACO group (7.7\% vs. $12.0 \%$, $\mathrm{p}=0.070)$, and airway wall thickness was higher in those with ACO (5.0 mm vs. $4.7 \mathrm{~mm}, \mathrm{p}=0.041)$. This study suggested that ventilation abnormalities are different in patients with ACO and COPD; thus, physiological changes in these two groups of patients may be assessed using imaging methods. 


\section{Prognosis of ACO}

\section{Changes in lung function}

The Canadian Cohort Obstructive Lung Disease (CanCOLD) study reported faster $\mathrm{FEV}_{1}$ decliners were more frequently observed in $\mathrm{ACO}^{31}$ and GINA, and explained that there was broad agreement for more rapid lung function decline in ACO than in those with asthma or COPD alone ${ }^{2}$. However, there was still insufficient evidence for a change in the lung function of ACO. In addition, several Korean ACO studies reported conflicting results on lung function change.

In the COREA cohort, which estimated the lung function changes after 1 and 3 years, the ACO group showed greater $\mathrm{FEV}_{1}$ and FVC decline than the asthma group only ${ }^{4}$. In COPD studies, conflicting results were reported for changes in lung function in patients with ACO. Sin et al. ${ }^{8}$ defined ACO based on the ATS roundtable criteria in the KOLD cohort. The FEV changes between those with ACO $(n=47)$ and COPD $(n=192)$ for a median of 5.8-year follow-up were compared. The rate of $\mathrm{FEV}_{1}$ change was $-13.9 \mathrm{~mL} / \mathrm{yr}$ in those with $\mathrm{ACO}$, and -29.3 $\mathrm{mL} / \mathrm{yr}$ in those with COPD; a favorable outcome was identified in terms of lung function decline in $\mathrm{ACO}^{22}$. Park et al. ${ }^{12}$ also reported favorable $\mathrm{FEV}_{1}$ changes over a 3-year follow-up in patients with ACO according to the BDR positivity criteria in the KOCOSS cohort. However, another study of the KOCOSS cohort reported that ACO patients, defined according to four sets of diagnostic criteria, experienced greater $\mathrm{FEV}_{1}$ decline than those with COPD in two distinct criteria for $\mathrm{ACO}^{32}$.

\section{Exacerbation risk}

The risk of exacerbation across the ACO studies is summarized in Table 2. Lee et al. ${ }^{33}$ reported that concomitant self-reported physician-diagnosed asthma was an independent risk factor for severe exacerbation of COPD through the KNHANES database (adjusted odds ratio, 1.67). Several other studies also reported a higher future exacerbation risk in individuals with ACO than in those with asthma or COPD alone. In the COREA cohort, individuals with ACO experienced more exacerbations at 1 year ( 1.61 vs. 2.38, respectively; $\mathrm{p}<0.001)$ and 3 years ( 0.73 vs. $0.65, \mathrm{p}=0.07)$ follow-up compared to those with asthma alone $e^{4}$ In COPD studies, ACO defined according to the GINA guideline reported a high rate of hospitalizations for those with $\mathrm{ACO}^{6}$, and ACO in the $\mathrm{KO}$ COSS cohort, defined according to four sets of diagnostic criteria, experienced more exacerbations compared with COPD alone $^{10}$. In the KNHANES database, self-reported wheezing and smoking history-based COPD-predominant ACO patients experienced more severe exacerbations compared to both normal and smokers (adjusted hazard ratio [HR], 1.79 and 2.11 , respectively $)^{17}$. Park et al. ${ }^{12}$ reported a lower exacerbation risk in patients with ACO than in those with COPD alone. This study used only the BDR positivity criterion to define ACO in the KOCOSS cohort. However, Jo et al. ${ }^{18}$ reported no significant difference in the exacerbation risk between ACO and COPD alone in a later study analyzing the KOCOSS cohort, although the authors assessed the risk for exacerbation at the 6-month follow-up. Recently, Kim et al. ${ }^{34}$ reported that asthma as a comorbid condition of COPD was associated with exacerbation in the NHI Service-National Sample Cohort (odds ratio, 1.57).

\section{Mortality}

The long-term outcomes of ACO in terms of mortality have been investigated in both population-based and cohort studies, with conflicting results. Population-based studies have reported higher mortality in ACO patients ${ }^{35-37}$, but some cohort studies reported lower mortality in ACO patients ${ }^{38-40}$. However, there are insufficient long-term data related to the mortality of ACO in Korea.

Lee et al. ${ }^{41}$ conducted a retrospective cohort study using the KNHANES database, and found that chronic corticosteroiddependent asthmatics aged 40 years of age or older had higher mortality when they had concomitant COPD than in those without COPD (9,955/100,000 person-years vs. 5,585/100,100 person-years, $\mathrm{p}<0.001$ and adjusted HR, 1.29). Another retrospective, single-center study involving 2,933 COPD patients, among which 767 were ACO, reported that ACO patients had a significantly higher mortality rate than patients with COPD alone ( $54.9 \%$ vs. $45.1 \%$, respectively; $\mathrm{p}<0.001)^{6}$. In a recent population-based cohort study based on 3,127 ACO and 31,868 COPD patients followed up for 4 years, Lee et al. ${ }^{42}$ reported that exposure to particulate matter $\left(\mathrm{PM}_{10}\right)$ caused an increase in non-accidental mortality in all COPD patients, especially those diagnosed with ACO within the 1-, 3-, and 6-month follow-up periods. In addition, the adverse effects of $\mathrm{PM}_{10}$ exposure were more prominent in females (HR, 1.153) and never smokers (HR, 1.151).

\section{Healthcare resource use and cost}

ACO defined by fulfilling both the ICD-10 codes for COPD and asthma ${ }^{19}$, or by COPD plus self-reported wheezing criteria $^{43}$ through the NHI database, reported significantly higher medical costs and longer total length of healthcare resource use in both outpatient and inpatient services among ACO patients. Another population-based cohort study also reported significantly greater medical costs in patients with COPDpredominant $\mathrm{ACO}^{17}$. 
Table 2. The risk of exacerbation in ACO

\begin{tabular}{|c|c|c|c|c|}
\hline Citation & No. of patients & Definition of ACO & $\begin{array}{l}\text { Duration of } \\
\text { follow-up (yr) }\end{array}$ & Exacerbation risk statistics \\
\hline $\begin{array}{l}\text { Kim et al. } \\
(2015)^{6}\end{array}$ & $\begin{array}{l}\text { 2,933 COPD } \\
\text { patients }\end{array}$ & $\begin{array}{l}\text { Post-BD FEV } \mathrm{F}_{1} / \mathrm{FVC}<0.7 \text { and asthma was } \\
\text { diagnosed based on GINA definition }\end{array}$ & 10 & $\begin{array}{l}\text { Hospitalization than COPD-only group } \\
31.3 \% \text { vs. } 13.0 \%, p<0.001\end{array}$ \\
\hline $\begin{array}{l}\text { Jo et al. } \\
\quad(2017)^{10}\end{array}$ & $\begin{array}{l}301 \mathrm{COPD} \\
\text { patients }\end{array}$ & $\begin{array}{l}\text { Modified Spanish criteria ( } 7 \text { ) } \\
\text { ATS Roundtable criteria (8) } \\
\text { PLATINO criteria (9) } \\
\text { GINA/GOLD criteria ( } 2017 \text { updated) }\end{array}$ & 1 & $\begin{array}{l}\text { Moderate to severe exacerbation compared } \\
\text { to non-ACO COPD } \\
\text { Adjusted HR (95\% CI) } \\
1.97(1.14-3.41) \\
1.07(0.2-5.82) \\
1.35(0.81-2.25) \\
2.01(0.97-4.15)\end{array}$ \\
\hline $\begin{array}{l}\text { Park et al. } \\
(2017)^{12}\end{array}$ & $\begin{array}{l}\text { 1,504 COPD } \\
\text { patients }\end{array}$ & $\begin{array}{l}\text { Post-BD } \mathrm{FEV}_{1} / \mathrm{FVC}<0.7 \text { and } \mathrm{BDR}>200 \\
\mathrm{~mL} \text { and } 12 \%\end{array}$ & 2 & $\begin{array}{l}\text { Any AE required systemic corticosteroid, } \\
\text { antibiotics or both in pure COPD vs. ACO } \\
\text { After } 1 \text { yr: } 20.9 \% \text { vs. } 18.0 \%(\mathrm{p}=0.461) \\
\text { After } 2 \text { yr: } 19.7 \text { vs. } 14.3 \%(\mathrm{p}=0.144) \\
\text { Severe AE requiring hospitalization in pure } \\
\text { COPD vs. ACO } \\
\text { After } 1 \text { yr: } 5.5 \text { vs. } 1.5 \%(\mathrm{p}=0.030) \\
\text { After } 2 \text { yr: } 5.6 \text { vs. } 0.8 \%(\mathrm{p}=0.015)\end{array}$ \\
\hline $\begin{array}{l}\text { Kim et al. } \\
(2018)^{17}\end{array}$ & $\begin{array}{l}\text { 2,269 of } \\
\text { KNHANES } \\
\text { database }\end{array}$ & $\begin{array}{l}\mathrm{FEV}_{1} / \mathrm{FVC}<0.7 \text { and } \mathrm{FEV}_{1} \geq 50 \% \text { and } \\
\text { self-reported wheezing }(\mathrm{W}+)^{*} \\
\text { Self-reported wheezing }(\mathrm{W}+) \text { with/ } \\
\text { without Smoking }\left(\mathrm{S}_{+}\right)^{*} ; \mathrm{W}+\mathrm{S}-\text { and } \\
\mathrm{W}+\mathrm{S}+\text { were asthma-predominant } \\
\text { ACO and COPD-predominant ACO, } \\
\text { respectively. }\end{array}$ & 6 & $\begin{array}{l}\text { aHR } 1.58(95 \% \text { CI, } 0.95-2.63) \text { and } 2.11 \text { ( } 95 \% \\
\text { CI, } 1.43-3.10) \text { compared to the W-S- \& } \\
\text { W-S+ group in COPD-predominant ACO } \\
(\mathrm{W}+\mathrm{S}+)\end{array}$ \\
\hline $\begin{array}{l}\text { Song et al. } \\
(2018)^{21}\end{array}$ & $\begin{array}{l}\text { 1,383 COPD } \\
\text { patients }\end{array}$ & $\begin{array}{l}\text { Modified Spanish (7) } \\
\text { ATS Roundtable (8) }\end{array}$ & 1 & $\begin{array}{l}\text { Moderate to severe exacerbation compared } \\
\text { to non-ACO COPD } \\
\text { aHR } 0.73(95 \% 0.50-1.08) \text { and } 0.63(95 \% \mathrm{CI} \text {, } \\
0.19-2.10)\end{array}$ \\
\hline $\begin{array}{l}\text { Park et al. } \\
(2019)^{4}\end{array}$ & $\begin{array}{l}959 \text { Asthma } \\
\text { patients }\end{array}$ & $\begin{array}{l}\text { BDR }>200 \mathrm{~mL} \text { and } 12 \% \text { or positive } \\
\text { provocation test }^{\dagger} \text { and post-BD } \\
\mathrm{FEV}_{1} / \mathrm{FVC}<0.70\end{array}$ & 3 & $\begin{array}{l}\text { Moderate to severe exacerbation compared } \\
\text { to asthma only } \\
\text { After } 1 \text { yr: } 2.38 \text { vs. } 1.61, \mathrm{p}<0.001 \\
\text { After } 3 \text { yr: } 0.65 \text { vs. } 0.73, \mathrm{p}=0.070\end{array}$ \\
\hline
\end{tabular}

*Smoking ( $\mathrm{S}+$ ) was defined a current or an ex-smoker who had smoked $\geq 100$ cigarettes. ${ }^{\dagger}$ Positive methacholine results were defined as the provocative concentration of methacholine required to decrease $\mathrm{FEV}_{1}\left(\mathrm{PC}_{20}\right)$ by $20 \%$ less than or equal to $16 \mathrm{mg} / \mathrm{mL}$ and Positive mannitol results were defined as $\mathrm{PD}_{15}$ less than or equal to $635 \mathrm{mg}$.

ACO: asthma-chronic obstructive pulmonary disease overlap; COPD: chronic obstructive pulmonary disease; BD: bronchodilator; FEV forced expiratory volume in 1 second; FVC: forced vital capacity; GINA: Global Initiative for Asthma; ATS: American Thoracic Society; PLATINO: Spanish acronym for the Latin American Project for Research in Pulmonary Obstruction; GOLD: Global Initiative for COPD; HR: hazard ratio; CI: confidence interval; BDR: bronchodilator response; AE: acute exacerbation; KNHANES: Korean National Health, and Nutrition Examination Survey; aHR: adjusted hazard ratio.

\section{Treatment and Clinical Impact on Outcomes}

\section{Treatment status of ACO in clinical practice}

There was no significant difference in inhaled corticosteroid (ICS)/long-acting beta-2 receptor agonist (LABA), leukotriene receptor antagonist (LTRA), and omalizumab (anti-IgE) prescription in ACO, despite the administration of the long-acting muscarinic receptor agonist (LAMA), xanthine. More system- ic steroids were administered to those with ACO compared to those with severe asthma ${ }^{5}$. In contrast, more ICS-containing maintenance inhaler therapy was prescribed to patients with ACO than to those with COPD alone ${ }^{6,13,17,19,22}$. However, conflicting results were reported regarding the use of LAMA. A single COPD cohort study and a KNHANES database-derived study reported less LAMA use in ACO than in $\mathrm{COPD}^{6,11}$. However, another study of KNHANES that defined ACO according to subjective wheezing found that LAMA, LTRA, and even oral corticosteroids were more frequently prescribed to patients 
with ACO than those with COPD alone ${ }^{17}$.

There were differences in the frequency of medications used, even among ACO patients in a single-center cohort, due to the heterogeneity of ACO itself ${ }^{44}$. Patients with ACO were subdivided into four groups according to their blood eosinophil count of 300 cells $/ \mathrm{mL}$ and 10 PYs. ACO with fewer PYs tended to be female, and ICS/LABA and LTRA were the most frequently prescribed. However, ACO with more PYs smoking tended to be male and ICS/LABA was prescribed the most, but LAMA was also frequently used, and LTRA was less prescribed.

\section{Effect of ICS treatment on lung function and future exacerbation}

Several studies have analyzed the effects of treatment on prognosis, including lung function and exacerbation, which are summarized in Table 3.

Lim et al. ${ }^{45}$ analyzed the effect of ICS use on exacerbation and lung function changes in patients with ACO in a COPD cohort. In this study, ACO defined according to BDR or AHR positivity was divided into two groups: ACO with ICS treatment $(\mathrm{n}=90)$, and ACO without ICS treatment $(\mathrm{n}=35)$. As a result, ICS treatment had no beneficial effect on severe exacerbation (adjusted incidence rate ratio [IRR], 1.24 [95\% confidence interval (CI), 0.44-3.46]) and $\mathrm{FEV}_{1}$ decline $(-9.61 \mathrm{~mL} /$

Table 3. Treatment and impact of outcome

\begin{tabular}{|c|c|c|c|c|}
\hline Citation & Study design & Definition of ACO & Treatment & Results \\
\hline $\begin{array}{l}\text { Lim et al. } \\
(2014)^{45}\end{array}$ & $\begin{array}{l}\text { Retrospective } \\
\text { cohort study }\end{array}$ & $\begin{array}{l}\text { Smoking } \mathrm{PY} \geq 10 \text { and post- } \\
\mathrm{BD} \mathrm{FEV}_{1} / \mathrm{FVC}<0.7 \text { and BDR } \\
>200 \mathrm{~mL} \text { and } 12 \% \text { or positive } \\
\text { provocation test* }^{*}\end{array}$ & $\begin{array}{l}\text { ICS use (n=90) vs. non- } \\
\text { ICS use }(n=35) \text { in ACO } \\
\text { patients }\end{array}$ & $\begin{array}{l}\mathrm{FEV}_{1} \text { decline: no significant differences } \\
(9.61 \mathrm{~mL} / \mathrm{yr} \text { vs. } 15.68 \mathrm{~mL} / \mathrm{yr} \text { in ICS vs. non- } \\
\text { ICS group, } \mathrm{p}=0.598) \\
\text { Exacerbation: no reduction in severe } \\
\text { exacerbation (adjusted incidence rate } \\
\text { ratio, } 1.24 ; 95 \% \mathrm{CI}, 0.44-3.46) \\
\text { Time to death: no differences }\end{array}$ \\
\hline $\begin{array}{l}\text { Lee et al. } \\
\qquad(2016)^{46}\end{array}$ & $\begin{array}{l}\text { Retrospective } \\
\text { cohort study }\end{array}$ & $\begin{array}{l}\text { Smoking PY }>10 \text { and post-BD } \\
\mathrm{FEV}_{1} / \mathrm{FVC}<0.70 \text { and history } \\
\text { of asthma, and self-reported } \\
\text { wheezing within } 1 \text { year and } \\
\text { BDR }>200 \mathrm{~mL} \text { and } 12 \%\end{array}$ & $\begin{array}{l}\text { ICS/LABA on ACO }(n=45) \\
\text { vs. COPD }(n=107)\end{array}$ & $\begin{array}{l}\mathrm{FEV}_{1} \text { decline: favorable in ACO }(240.2 \mathrm{~mL} \\
\text { vs. } 124.6 \mathrm{~mL} \text { in ACO vs. COPD, } \mathrm{p}=0.002) \\
\text { Mild to moderate AFL: } 223 \mathrm{~mL} \text { vs. } 84.6 \mathrm{~mL} \text {, } \\
\text { p=0.005 } \\
\text { More than severe AFL: } 268.2 \mathrm{~mL} \text { vs. } 197.1 \\
\text { mL, } \mathrm{p}=0.209 \\
\text { Exacerbation: no significant differences } \\
(15.0 \% \text { vs. } 12.2 \%, \mathrm{p}=0.719)\end{array}$ \\
\hline $\begin{array}{l}\text { Jo et al. } \\
(2020)^{13}\end{array}$ & $\begin{array}{l}\text { Retrospective } \\
\text { cohort study }\end{array}$ & $\begin{array}{l}\text { GINA/GOLD guideline } \\
\text { ATS roundtable } \\
\text { Modified Spanish } \\
\text { Updated Spanish } \\
\text { Specialist's judgment }\end{array}$ & $\begin{array}{l}\text { ICS use vs. non-ICS use in } \\
\text { ACO } \\
81 \text { vs. } 57 \text { in GINA/GOLD } \\
21 \text { vs. } 11 \text { in ATS } \\
74 \text { vs. } 97 \text { in modified } \\
\text { Spanish } \\
93 \text { vs. } 128 \text { in updated } \\
\text { Spanish } \\
152 \text { vs. } 112 \text { in specialists' } \\
\text { decision }\end{array}$ & $\begin{array}{l}\text { Exacerbation: reduced moderate to severe } \\
\text { exacerbation in ACO according to the } \\
\text { specialists' diagnoses and the GINA/ } \\
\text { GOLD criteria } \\
\text { Adjusted IRR, } 0.34 \text { ( } 95 \% \text { CI, } 0.17-0.69) \text { and } \\
0.61(0.39-0.95) \text {, respectively }\end{array}$ \\
\hline $\begin{array}{l}\text { Park et al. } \\
(2021)^{47}\end{array}$ & $\begin{array}{l}\text { Randomized, } \\
\text { noninferiority } \\
\text { trial }\end{array}$ & $\begin{array}{l}\text { Post-BD FEV } / / F V C<0.7 \text { and } \\
\text { BDR }>200 \mathrm{~mL} \text { and } 12 \% \text { or } \\
\text { positive provocation test* } \\
\text { Only ACO with } \mathrm{FEV}_{1}>30 \% \\
\text { and moderate to high dose } \\
\text { of ICS/LABA were enrolled }\end{array}$ & $\begin{array}{l}\text { ICS/LABA }(n=154) \text { vs. ICS/ } \\
\text { LABA/LAMA }(n=149) \text { in } \\
\text { ACO patients }\end{array}$ & $\begin{array}{l}\text { Exacerbation: } 18.8 \% \text { (29/154) vs. } 18.8 \% \\
\text { (28/149) in ICS/LABA vs. ICS/LABA/ } \\
\text { LAMA (HR, 1.1; 95\% CI, } 0.6-1.84 \text { ) } \\
\text { FEV }_{1} \text { change: } 0.017 \text { L vs. } 0.108 \mathrm{~L}, \mathrm{p}=0.023 \text { in } \\
\text { ICS/LABA vs. ICS/LABA/LAMA }\end{array}$ \\
\hline
\end{tabular}

*Positive methacholine results were defined as the provocative concentration of methacholine required to decrease $\mathrm{FEV}_{1}\left(\mathrm{PC}_{20}\right)$ by $20 \%$ less than or equal to $16 \mathrm{mg} / \mathrm{mL}$ and positive mannitol results were defined as $\mathrm{PD}_{15}$ less than or equal to $635 \mathrm{mg}$.

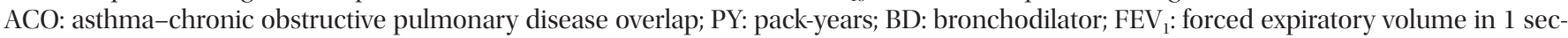
ond; FVC: forced vital capacity; BDR: bronchodilator response; ICS: inhaled corticosteroid; CI: confidence interval; LABA: long-acting $\beta 2$ receptor agonist; COPD: chronic obstructive pulmonary disease; AFL: airflow limitation; GINA: Global Initiative for Asthma; GOLD: Global Initiative for COPD; ATS: American Thoracic Society; IRR: incident rate ratio; LAMA: long-acting muscarinic receptor agonist; HR: hazard ratio. 
yr vs. $-15.68 \mathrm{~mL} / \mathrm{yr}$ in the ICS vs. non-ICS treatment group, respectively; $\mathrm{p}=0.598)$. However, Lee et al. ${ }^{46}$ reported ICS/ LABA (fixed-dose $50 \mu \mathrm{g}$ salmeterol/500 $\mu \mathrm{g}$ fluticasone or 9 $\mu \mathrm{g}$ formoterol/320 $\mu \mathrm{g}$ budesonide, twice daily) treatment for three months improved $\mathrm{FEV}_{1}$ and $\mathrm{FVC}$ better in those with ACO compared to those with COPD alone $\left(\mathrm{FEV}_{1}, 240.2 \mathrm{~mL}\right.$ vs. $124.6 \mathrm{~mL}, \mathrm{p}=0.002$; FVC, $304.8 \mathrm{~mL}$ vs. $150.2 \mathrm{~mL}$; $\mathrm{p}=0.030$ ), and this beneficial effect was robust in the mild to moderate airflow limitation group.

Using five sets of diagnostic criteria in the KOCOSS cohort, ICS treatment decreased the risk of exacerbation in ACO for two sets of criteria (IRR, 0.55 and 0.69 in specialists' diagnosis and GINA/GOLD criteria; $\mathrm{p}<0.05$ for both). The authors also suggested that, among COPD patients, the only factor associated with the reduction of exacerbation risk by ICS treatment was a high blood eosinophil count $(\geq 300 \text { cells } / \mathrm{mL})^{13}$.

\section{Effect of LAMA add-on to ICS/LABA on prognosis}

Recently, a multicenter randomized trial of 303 ACO patients who defined ACO as positive BDR or AHR and $\mathrm{FEV}_{1} /$ $\mathrm{FVC}<0.7$ and whose $\mathrm{FEV}_{1}>30 \%$ with moderate to high dose ICS/LABA treatment, was conducted. The times to first exacerbation between ACO with ICS/LABA $(n=154)$ and LAMA added to ICS/LABA $(n=149)$ were analyzed ${ }^{47}$. There was no significant difference in exacerbation events (HR, 1.1; 95\% CI, 0.66-1.84); however, $\mathrm{FEV}_{1}$ and FVC improved significantly in the LAMA add-on group $\left(0.017 \mathrm{~L}\right.$ vs. $0.108 \mathrm{~L}_{\text {for }} \mathrm{FEV}_{1}$ and $-0.004 \mathrm{~L}$ vs. $0.125 \mathrm{~L}$ for FVC; $\mathrm{p}<0.05$ for both).

\section{Conclusion}

In conclusion, despite the lack of consensus regarding the definition and recognition of ACO as a distinct disease entity with a distinct pathophysiological background, many Korean physicians have devoted attention to ACO. This may be due to the need for appropriate therapy for patients because the clinical features and prognosis of ACO are somewhat different from those of asthma and COPD. In South Korea, ACO research has been conducted in various fields and has shown similar characteristics to the previously known group of ACO patients. This is important because an appropriate identification of patients with ACO may allow better-targeted therapy, and could improve the clinical course. For prognoses, such as lung function changes and the effect of therapies, additional research using long-term data and consistent criteria for patient classification will be needed.

\section{Conflicts of Interest}

No potential conflict of interest relevant to this article was reported.

\section{Funding}

No funding to declare.

\section{References}

1. Gibson PG, Simpson JL. The overlap syndrome of asthma and COPD: what are its features and how important is it? Thorax 2009;64:728-35.

2. Global Initiative for Asthma. Global strategy for asthma management and prevention: 2021 upeate [Internet]. Fontana: Global Initiative for Asthma; 2021 [cited 2021 Mar 15]. Available from: http://www.ginasthma.org.

3. Lee HY, Kang JY, Yoon HK, Lee SY, Kwon SS, Kim YK, et al. Clinical characteristics of asthma combined with COPD feature. Yonsei Med J 2014;55:980-6.

4. Park SY, Jung H, Kim JH, Seo B, Kwon OY, Choi S, et al. Longitudinal analysis to better characterize Asthma-COPD overlap syndrome: findings from an adult asthma cohort in Korea (COREA). Clin Exp Allergy 2019;49:603-14.

5. Lee H, Kim SH, Kim BK, Lee Y, Lee HY, Ban GY, et al. Characteristics of specialist-diagnosed asthma-COPD overlap in severe asthma: observations from the Korean Severe Asthma Registry (KoSAR). Allergy 2021;76:223-32.

6. Kim MA, Noh CS, Chang YJ, Hong YK, Lee JS, Lee SW, et al. Asthma and COPD overlap syndrome is associated with increased risk of hospitalisation. Int J Tuberc Lung Dis 2015;19:864-9.

7. Cosio BG, Soriano JB, Lopez-Campos JL, Calle-Rubio M, Soler-Cataluna JJ, de-Torres JP, et al. Defining the asthma-COPD overlap syndrome in a COPD cohort. Chest 2016;149:45-52.

8. Sin DD, Miravitlles M, Mannino DM, Soriano JB, Price D, Celli $\mathrm{BR}$, et al. What is asthma-COPD overlap syndrome? Towards a consensus definition from a round table discussion. Eur Respir J 2016;48:664-73.

9. Menezes AM, Montes de Oca M, Perez-Padilla R, Nadeau G, Wehrmeister FC, Lopez-Varela MV, et al. Increased risk of exacerbation and hospitalization in subjects with an overlap phenotype: COPD-asthma. Chest 2014;145:297-304.

10. Jo YS, Lee J, Yoon HI, Kim DK, Yoo CG, Lee CH. Different prevalence and clinical characteristics of asthma-chronic obstructive pulmonary disease overlap syndrome according to accepted criteria. Ann Allergy Asthma Immunol 2017;118: 696-703.

11. Lee JH, Rhee CK, Kim K, Kim JA, Kim SH, Yoo KH, et al. Identification of subtypes in subjects with mild-to-moderate airflow limitation and its clinical and socioeconomic implications. Int J Chron Obstruct Pulmon Dis 2017;12:1135-44.

12. Park HJ, Byun MK, Kim HJ, Ahn CM, Lee JH, Shin KC, et al. 
Asthma-COPD overlap shows favorable clinical outcomes compared to pure COPD in a Korean COPD cohort. Allergy Asthma Immunol Res 2017;9:431-7.

13. Jo YS, Hwang YI, Yoo KH, Kim TH, Lee MG, Lee SH, et al. Effect of inhaled corticosteroids on exacerbation of asthmaCOPD overlap according to different diagnostic criteria. J Allergy Clin Immunol Pract 2020;8:1625-33.

14. Crapo RO, Casaburi R, Coates AL, Enright PL, Hankinson JL, Irvin CG, et al. Guidelines for methacholine and exercise challenge testing-1999. This official statement of the American Thoracic Society was adopted by the ATS Board of Directors, July 1999. Am J Respir Crit Care Med 2000;161:309-29.

15. Anderson SD, Charlton B, Weiler JM, Nichols S, Spector SL, Pearlman DS, et al. Comparison of mannitol and methacholine to predict exercise-induced bronchoconstriction and a clinical diagnosis of asthma. Respir Res 2009;10:4.

16. Plaza V, Alvarez F, Calle M, Casanova C, Cosio BG, Lopez-Vina A, et al. Consensus on the Asthma-COPD Overlap Syndrome (ACOS) between the Spanish COPD guidelines (GesEPOC) and the Spanish Guidelines on the Management of Asthma (GEMA). Arch Bronconeumol 2017;53:443-9.

17. Kim MH, Rhee CK, Kim K, Kim SH, Lee JY, Kim YH, et al. Heterogeneity of asthma and COPD overlap. Int J Chron Obstruct Pulmon Dis 2018;13:1251-60.

18. Jo YS, Hwang YI, Yoo KH, Kim TH, Lee MG, Lee SH, et al. Comparing the different diagnostic criteria of asthma-COPD overlap. Allergy 2019;74:186-9.

19. Rhee CK, Yoon HK, Yoo KH, Kim YS, Lee SW, Park YB, et al. Medical utilization and cost in patients with overlap syndrome of chronic obstructive pulmonary disease and asthma. COPD 2014;11:163-70.

20. Kang HR, Hong SH, Ha SY, Kim TB, Lee EK. Differences in the risk of mood disorders in patients with asthma-COPD overlap and in patients with COPD alone: a nationwide population-based retrospective cohort study in Korea. Respir Res 2019;20:80.

21. Song JH, Lee CH, Kim DK, Yoon H, Byun MK, Rhee CK, et al. Differences in prevalence of asthma-COPD overlap according to different criteria. Medicine (Baltimore) 2018;97:e12049.

22. Park HY, Lee SY, Kang D, Cho J, Lee H, Lim SY, et al. Favorable longitudinal change of lung function in patients with asthmaCOPD overlap from a COPD cohort. Respir Res 2018;19:36.

23. Lee DW, Choi EY. A comparative study of bone mineral density among patients with obstructive lung diseases in Korea. Int J Tuberc Lung Dis 2015;19:1246-51.

24. Lee DW, Jin HJ, Shin KC, Chung JH, Lee HW, Lee KH. Presence of sarcopenia in asthma-COPD overlap syndrome may be a risk factor for decreased bone-mineral density, unlike asthma: Korean National Health and Nutrition Examination Survey (KNHANES) IV and V (2008-2011). Int J Chron Obstruct Pulmon Dis 2017;12:2355-62.

25. Miravitlles M, Alvarez-Gutierrez FJ, Calle M, Casanova C, Cosio BG, Lopez-Vina A, et al. Algorithm for identification of asthma-COPD overlap: consensus between the Spanish COPD and asthma guidelines. Eur Respir J 2017;49:1700068.

26. Oh JY, Lee YS, Min KH, Hur GY, Lee SY, Kang KH, et al. Increased urinary l-histidine in patients with asthma-COPD overlap: a pilot study. Int J Chron Obstruct Pulmon Dis 2018; 13:1809-18.

27. Oh JY, Lee YS, Min KH, Hur GY, Lee SY, Kang KH, et al. Decreased serum club cell secretory protein in asthma and chronic obstructive pulmonary disease overlap: a pilot study. Int J Chron Obstruct Pulmon Dis 2018;13:3411-7.

28. Jo YS, Kwon SO, Kim J, Kim WJ. Neutrophil gelatinase-associated lipocalin as a complementary biomarker for the asthmachronic obstructive pulmonary disease overlap. J Thorac Dis 2018;10:5047-56

29. Lee YK, Oh YM, Lee JH, Kim EK, Lee JH, Kim N, et al. Quantitative assessment of emphysema, air trapping, and airway thickening on computed tomography. Lung 2008;186:157-65.

30. Hwang HJ, Lee SM, Seo JB, Lee JS, Kim N, Lee SW, et al. Visual and quantitative assessments of regional xenon-ventilation using dual-energy CT in asthma-chronic obstructive pulmonary disease overlap syndrome: a comparison with chronic obstructive pulmonary disease. Korean J Radiol 2020;21: 1104-13.

31. Barrecheguren M, Pinto L, Mostafavi-Pour-Manshadi SM, Tan WC, Li PZ, Aaron SD, et al. Identification and definition of asthma-COPD overlap: The CanCOLD study. Respirology 2020;25:836-49.

32. Lim JU, Kim DK, Lee MG, Hwang YI, Shin KC, In KH, et al. Clinical characteristics and changes of clinical features in patients with asthma-COPD overlap in Korea according to different diagnostic criteria. Tuberc Respir Dis (Seoul) 2020; 83(Suppl 1):S34-S45.

33. Lee H, Rhee CK, Lee BJ, Choi DC, Kim JA, Kim SH, et al. Impacts of coexisting bronchial asthma on severe exacerbations in mild-to-moderate COPD: results from a national database. Int J Chron Obstruct Pulmon Dis 2016;1 1:775-83.

34. Kim Y, Kim YJ, Kang YM, Cho WK. Exploring the impact of number and type of comorbidities on the risk of severe COPD exacerbations in Korean population: a nationwide cohort study. BMC Pulm Med 2021;21:151.

35. Lange P, Colak Y, Ingebrigtsen TS, Vestbo J, Marott JL. Longterm prognosis of asthma, chronic obstructive pulmonary disease, and asthma-chronic obstructive pulmonary disease overlap in the Copenhagen City Heart study: a prospective population-based analysis. Lancet Respir Med 2016;4:454-62.

36. Kumbhare S, Strange C. Mortality in asthma-chronic obstructive pulmonary disease overlap in the United States. South Med J 2018;111:293-8.

37. Baarnes CB, Andersen ZJ, Tjonneland A, Ulrik CS. Incidence and long-term outcome of severe asthma-COPD overlap compared to asthma and COPD alone: a 35-year prospective study of 57,053 middle-aged adults. Int J Chron Obstruct Pulmon Dis 2017;12:571-9. 
38. van Boven JF, Roman-Rodriguez M, Palmer JF, Toledo-Pons N, Cosio BG, Soriano JB. Comorbidome, pattern, and impact of asthma-COPD overlap syndrome in real life. Chest 2016;149:1011-20.

39. Peltola L, Patsi H, Harju T. COPD comorbidities predict high mortality: asthma-COPD-overlap has better prognosis. COPD 2020;17:366-72.

40. Suzuki M, Makita H, Konno S, Shimizu K, Kimura H, Kimura H, et al. Asthma-like features and clinical course of chronic obstructive pulmonary disease: an analysis from the Hokkaido COPD cohort study. Am J Respir Crit Care Med 2016;194: 1358-65.

41. Lee H, Ryu J, Chung SJ, Park DW, Sohn JW, Yoon HJ, et al. Coexisting COPD increases mortality in patients with corticosteroid-dependent asthma: a nationwide population-based study. Allergy Asthma Immunol Res 2020;12:821-31.

42. Lee YM, Lee JH, Kim HC, Ha E. Effects of PM10 on mortality in pure COPD and asthma-COPD overlap: difference in exposure duration, gender, and smoking status. Sci Rep 2020;10: 2402.
43. Kim J, Kim YS, Kim K, Oh YM, Yoo KH, Rhee CK, et al. Socioeconomic impact of asthma, chronic obstructive pulmonary disease and asthma-COPD overlap syndrome. J Thorac Dis 2017;9:1547-56.

44. Joo H, Han D, Lee JH, Rhee CK. Heterogeneity of asthmaCOPD overlap syndrome. Int J Chron Obstruct Pulmon Dis 2017;12:697-703.

45. Lim HS, Choi SM, Lee J, Park YS, Lee SM, Yim JJ, et al. Responsiveness to inhaled corticosteroid treatment in patients with asthma-chronic obstructive pulmonary disease overlap syndrome. Ann Allergy Asthma Immunol 2014;113:652-7.

46. Lee SY, Park HY, Kim EK, Lim SY, Rhee CK, Hwang YI, et al Combination therapy of inhaled steroids and long-acting beta2-agonists in asthma-COPD overlap syndrome. Int J Chron Obstruct Pulmon Dis 2016;11:2797-803.

47. Park SY, Kim S, Kim JH, Kim SH, Lee T, Yoon SY, et al. A randomized, noninferiority trial comparing ICS + LABA with ICS + LABA + LAMA in asthma-COPD overlap (ACO) treatment: the ACO Treatment with Optimal Medications (ATOMIC) study. J Allergy Clin Immunol Pract 2021;9:1304-11. 